\title{
Investigation of antioxidant effects of rosmarinic acid on liver, lung and kidney in rats: a biochemical and histopathological study
}

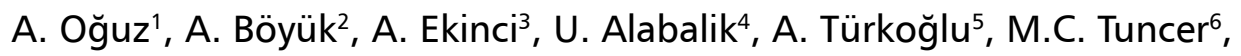 \\ A. Ekingen ${ }^{7}$, E. Deveci ${ }^{8}$, B. Gültürk ${ }^{9}$, U. Aday ${ }^{9}$ \\ ${ }^{1}$ Department of General Surgery, Faculty of Medicine, University of Dicle, Diyarbakır, Turkey \\ ${ }^{2}$ Department of General Surgery, University of Health Sciences Elazığ Training and Research Hospital, Elazı ğ, Turkey \\ ${ }^{3}$ Department of Biochemistry, Faculty of Medicine, University of Dicle, Diyarbakır, Turkey \\ ${ }^{4}$ Department of Pathology, Faculty of Medicine, University of Dicle, Diyarbakır, Turkey \\ ${ }^{5}$ Department of General Surgery, Medical Park Gaziantep Hospital, Gaziantep, Turkey \\ ${ }^{6}$ Department of Anatomy, Faculty of Medicine, University of Dicle, Diyarbakır, Turkey \\ ${ }^{7}$ Vocational High School of Health Services, University of Batman, Turkey \\ ${ }^{8}$ Department of Histology and Embryology, Faculty of Medicine, Dicle University, Diyarbakır, Turkey \\ ${ }^{9}$ Department of General Surgery, Elazığ Fethi Sekin City Hospital, Elazı̆̆, Turkey
}

[Received: 10 July 2019; Accepted: 29 July 2019]

Background: The aim of the study was to investigate the protective effects of rosmarinic acid in rats exposed to hepatic ischaemia/reperfusion (I/R) injury. Materials and methods: Thirty-two rats were randomly classified into four groups of 8 rats each: laparotomy without medication, rosmarinic acid (dose of $50 \mathrm{mg} / \mathrm{kg}$ via oral gavage) followed by laparotomy, laparotomy followed by hepatic $I / R$, and hepatic I/R with rosmarinic acid. Serum aspartate aminotransferase, alanine aminotransferase, and malondialdehyde levels and total oxidant activity and total antioxidant capacity levels of the liver, lung, and kidney were assessed. The histopathologic assessment was also performed.

Results: Rosmarinic acid significantly reduced liver function test parameters and decreased oxidative stress and abnormal histopathologic findings in the liver. The oxidative stress in the lung significantly increased in the I/R group but significantly decreased in the $I / R$ + rosmarinic acid group due to the addition of rosmarinic acid. Rosmarinic acid led to no reduction in oxidative stress in kidney following hepatic I/R injury. There were no statistically significant differences among the groups regarding histopathologic changes in kidney and lung sections.

Conclusions: Rosmarinic acid has antioxidant properties and is an effective hepatoprotective agent. However, although rosmarinic acid provides useful effects in the lung by increasing antioxidant capacity and reducing oxidative stress after I/R injury, it does not ameliorate histopathologic changes. These findings suggest that rosmarinic acid is likely to provide favourable outcomes in the treatment of hepatic I/R injury. (Folia Morphol 2020; 79, 2: 288-295)

Key words: hepatic ischaemia-reperfusion, rosmarinic acid, oxidant and antioxidant capacity, liver, kidney, lung 


\section{INTRODUCTION}

Hepatic ischaemia/reperfusion (I/R) injury represents an important complication, which is frequently encountered in clinical applications and causes impaired liver function and increased postoperative mortality and morbidity rates. I/R injury may result from hepatic pedicle clamping, also known as the Pringle maneuver, particularly during extensive hepatic trauma, liver transplantation, as well as the resection of large intrahepatic tumours. Hepatic I/R injury represents a complex pathophysiological process with multiple factors, in which inflammatory cytokines, polymorphonuclear neutrophils, and reactive oxygen species (ROS) are involved [14, 24, 29].

Oxygen deprivation triggers the development of ischaemia and release of ROS during reperfusion, resulting in cell death and cell dysfunction as well as ageing and age-related diseases at the organic level. To reduce the effect of ROS on biomolecules, aerobic organisms have produced numerous enzymatic as well as nonenzymatic antioxidants [1, 4, 20]. Experimental studies investigating hepatic $\mathrm{I} / \mathrm{R}$ injury have mainly dealt with the minimisation or prevention of the adverse impacts of $\mathrm{I} / \mathrm{R}$ injury on the lung and remote organs. Moreover, the literature shows that numerous drugs, as well as natural and chemical substances, have been utilised for the reduction of hepatic I/R injury. Furthermore, various herbs and fruit extracts have also been reported.

Herbal plants have been commonly used in the treatment of hepatic $\mathrm{l} / \mathrm{R}$ injury in numerous recent researches [4, 14, 24, 29]. Rosmarinic acid (RA) is a naturally occurring polyphenolic antioxidant found in numerous common herbal plants. RA is isolated from herbal balm mint plants, including Melissa officinalis, Rosmarinus officinalis, and Prunella vulgaris [12, $31,37]$. It has been shown that RA has antioxidant, anticarcinogenic, anti-inflammatory, antidepressant, and antimicrobial impacts [7, 8, 13, 22, 23, 29, 38].

Rosmarinic acid exerts its antioxidant effects indirectly by increasing the expression of cytoprotective genes, thereby influencing several enzymes of the antioxidant system. RA has been reported to reduce the oxidative and electrophilic cytotoxicity induced by xanthine oxidase and hydrogen peroxide $\left(\mathrm{H}_{2} \mathrm{O}_{2}\right)$, as well as the intracellular concentration of free oxygen radicals [22]. RA has also been shown to increase the production of prostaglandin E2, decrease the production of leukotriene B4, interleukin-6, interleukin-1beta, and tumour necrosis factor alpha, and inhibit the complement system [17, 34].
The effects of RA on chemical hypoxia have also been investigated. Nevertheless, the impacts of RA on hepatic l/R models have not been fully elucidated. In the present experimental study, it was aimed to assess the potential impacts of RA on the minimisation and/or prevention of $\mathrm{I} / \mathrm{R}$ injury in the distant organs and liver.

\section{MATERIALS AND METHODS}

\section{Animals}

All surgical procedures and the subsequent care and treatment of the animals used in this study were in strict accordance with the National Institutes of Health (NIH) guidelines for animal care (NIH Publication no. 85-23, revised 1996). All procedures performed in this experiment were approved by the Ethics Committee for the Treatment of Experimental Animals (Faculty of Medicine, University of Dicle, Turkey). Thirty-two male Wistar albino rats with the weight 250-300 g were provided by Dr. Sabahattin Payzin Health Sciences Application and Research Centre, Dicle University and their random selection was performed. The rats were kept in individual cages at constant temperature conditions $\left(21^{\circ} \mathrm{C}\right)$ with a 12-hour light/dark cycle. A standard diet and water ad libitum were given to them. All rats were fasted overnight. The rats of all groups were maintained in the same conditions. All rats at the end of the experiment were healthy and no difference in food/ /water consumption and body weight gain between experimental and control rats were observed.

\section{Experimental design and surgical procedures}

The experimental procedure was initiated by inducing anaesthesia with the intramuscular injection of $50 \mathrm{mg} / \mathrm{kg}$ ketamine hydrochloride (Eczacıbası, Istanbul) and $10 \mathrm{mg} / \mathrm{kg}$ xylazine (Rompun 2\%; Bayer). After the removal of the hair in the abdominal region, the skin was cleaned with $10 \%$ povidone-iodine solution. Laparotomy was applied to all of the rat groups. The liver, diaphragm, and organs adjacent to the hepatoduodenal ligament were carefully dissected, and the hepatoduodenal ligament was exposed and clamped using a microvascular clamp. The ligament suspension was performed for a period of $30 \mathrm{~min}$, and, in indicated groups, the Pringle maneuver was used for inducing ischaemia. After the 30-min ischaemic period, the opening of the suture was performed, and a 30-min period of reperfusion was initiated. After this period, blood was sampled from the heart 
at sacrifice. RA (catalogue number \# R4033-50MG, Sigma-Aldrich Inc.) was administered in the dose of $50 \mathrm{mg} / \mathrm{kg}$ via oral gavage (in accordance with Tmax) 30 min prior to the experimental examination in control and $\mathrm{I} / \mathrm{R}+\mathrm{RA}$ groups.

The rats were classified into four groups randomly:

- Sham group $(n=8)$ - the hepatoduodenal ligament was dissected, and no medications were administered;

- Control group $(n=8)$ - dissection was performed, and RA was administered in the dose of $50 \mathrm{mg} / \mathrm{kg}$ via oral gavage (in accordance with Tmax) $30 \mathrm{~min}$ prior to the experimental examination [12];

- I/R group ( $n=8)$ - reperfusion was made for the period of $30 \mathrm{~min}, 30 \mathrm{~min}$ following the Pringle maneuver, and no medications were administered;

- I/R + RA group $(n=8)$ - besides the procedures of Group III, RA was administered in the dose of $50 \mathrm{mg} / \mathrm{kg}$ via oral gavage (in accordance with Tmax) 30 min prior to the ischaemia period.

The collection of blood and samples (liver, both lungs, and kidneys) samples for analyses was performed in all groups. Plasma samples were acquired via blood centrifugation, inserted in plastic Eppendorf tubes with a cover for performing the biochemical analysis and kept at the temperature of $-80^{\circ} \mathrm{C}$ until being ready for the analysis. Preparation of the samples for conducting the biochemical analysis was performed. Afterwards, blood and foreign tissue residues were removed by flushing with saline. Subsequently, the samples were inserted in plastic Eppendorf tubes and kept at the temperature of $-80^{\circ} \mathrm{C}$ in a freezer. Finally, they were put into plastic containers containing $10 \%$ formaldehyde solution for histopathologic evaluation.

\section{Homogenisation of tissues}

The transfer of the samples kept at the temperature of $-80^{\circ} \mathrm{C}$ from the freezer to the laboratory was performed in dry ice. Pieces with the weight varying between 0.30 and $0.50 \mathrm{~g}$ were inserted in the tube, with the addition of $2 \mathrm{~mL}$ of Tris- $\mathrm{HCl}$ buffer. And then, they were kept on ice while their processing was performed in $50 \mathrm{mM} \mathrm{pH} 7.0$ phosphate-buffered saline for the period of 1-3 min at 14,000 rpm using a homogenizer (UltraTurrax Type T8, IKA Labortechnic, Staufen, Germany). Subsequently, the centrifugation of the homogenate was performed for the period of $30 \mathrm{~min}$ at the temperature of $4^{\circ} \mathrm{C}$, and supernatant samples were acquired for total oxidant activity (TOA), total antioxidant capacity (TAC) and oxidative stress index (OSI) analyses.

\section{Biochemical analysis}

The measurement of alanine aminotransferase (ALT), aspartate aminotransferase (AST), and malondialdehyde (MDA) in blood specimens was performed. TOA and TAC were measured in samples. Per cent ratio of TOS level to TAC level was accepted as OSI. OSI value was calculated.

\section{Malondialdehyde assays}

Malondialdehyde levels were assessed by measuring thiobarbituric acid (TBA) reactivity using the method developed by Hammouda [11]. Following the preparation of the sample and addition of $2.5 \mathrm{~mL} 10 \%(\mathrm{w} / \mathrm{v})$ TCA solution, $0.5 \mathrm{~mL}$ of distilled water and $0.5 \mathrm{~mL}$ sample were placed into the sample tube and were mixed by vortexing. The tubes were capped and warmed in a $90^{\circ} \mathrm{C}$ water bath for the period of $15 \mathrm{~min}$. Following the cooling period, the centrifugation of the tubes was performed for $10 \mathrm{~min}$ at $3000 \mathrm{~g}$, and $2 \mathrm{~mL}$ of supernatant was collected and added to $1 \mathrm{~mL}$ of $0.675 \%$ $(\mathrm{w} / \mathrm{v})$ TBA solution. Following the next $15 \mathrm{~min}$ in a $90^{\circ} \mathrm{C}$ water bath, cooling of the tubes was performed again. The absorbance of all specimens was read at $532 \mathrm{~nm}$ against an appropriate blank. The calculation of the serum MDA levels was performed as $\mu \mathrm{M}$ using standard graphs, which were produced using varying concentrations of 1,1,3,3-tetramethoxypropane.

\section{Assessment of total oxidant activity}

The TOA analysis represents a completely automatic colorimetric technique suggested by Erel [9]. The spectrophotometric measurement of colour intensity was performed using the above-mentioned method. The calculation of the TOA values were made as $\mathrm{nmol} \mathrm{H}_{2} \mathrm{O}_{2}$ equivalent/mg protein.

\section{Assessment of total antioxidant capacity}

The TAC represents a completely automatic technique suggested by Erel $[9,10]$ that measures antioxidant capacity against strong free radicals. The calculation of TAC values were calculated as $\mathrm{nmol}$ Trolox equivalent/mg protein.

\section{Assessment of the oxidative stress index}

The determination of the OSI was made based on the per cent rate of the TOA level to the TAC level. The calculation of OSI level was performed with the formu- 
la presented below [3]: OSI $=($ TOA $/ T A C) \times 100$. The results are given as arbitrary units. The OSI represents a parameter that indicates the extent of oxidative stress.

\section{Histologic examinations}

Haematoxylin-eosin (H\&E) staining procedure was as follows. Histopathologic analysis was performed on lung, liver, and kidney sections. $10 \%$ formalin was used for the fixation of the sections and they were embedded in paraffin. Tissue pieces were cut into the sections of 4-6 $\mu \mathrm{m}$ in thickness. After, the deparaffinisation procedure of sections with two changes of xylene for $10 \mathrm{~min}$ each they were re-hydrated in two changes of absolute alcohol, 5 min each. Applied with $95 \%$ alcohol for $2 \mathrm{~min}$ and $70 \%$ alcohol for 2 min sections were washed briefly in distilled water. Then, stained in Harris haematoxylin solution for $8 \mathrm{~min}$. Washing in running tap water for $5 \mathrm{~min}$, sections were differentiated in $1 \%$ acid alcohol for $30 \mathrm{~s}$. Bluing in $0.2 \%$ ammonia water for $30 \mathrm{~s}$ they were washed in running tap water for $5 \mathrm{~min}$ and rinsed in $95 \%$ alcohol. Counterstained in eosin-phloxine solution for $30 \mathrm{~s}$ and dehydrated through $95 \%$ alcohol, two changes of absolute alcohol, $5 \mathrm{~min}$ each. They were cleared in two changes of xylene, $5 \mathrm{~min}$ each and mounted with xylene based mounting medium.

Hepatic damage was determined using the following grading system: grade $\mathbf{0}-$ no damage; grade $\mathbf{1}$ - mild damage with nuclear pyknosis and cytoplasmic vacuolisation; grade $\mathbf{2}$ - moderate change accompanied by expanded nuclear pyknosis, vacuolisation, and cytoplasmic hypereosinophilia, sinusoidal dilatation and congestion, and the loss of intercellular borders; grade 3 - severe damage accompanied by neutrophil infiltration, haemorrhage and coagulative necrosis with the disintegration of and haemorrhage into hepatic cords leading to the loss of tissue architecture [15].

The grading system suggested by Koksel et al. [16] was employed for the determination of the lung injury severity, while the grading system suggested by Chatterjee et al. [5] was used for the determination of the kidney injury severity:

Lung injuries secondary to hepatic $I / R$ injury were classified as follows: grade $\mathbf{0}-$ no damage; grade 1 - mild neutrophil leukocyte infiltration and mild-moderate interstitial congestion; grade 2 moderate neutrophil leukocyte infiltration, perivascular oedema formation and disintegration of the pulmonary structure; grade $\mathbf{3}$ - dense neutrophil leukocyte infiltration and absolutely destruction of pulmonary structure.
Kidney injuries secondary to hepatic $\mathrm{I} / \mathrm{R}$ injury were classified as follows: grade $\mathbf{0}-$ no changes; grade 1 - swelling of tubular cells, loosing of brush edges, from nuclear condensation which is showing nuclear loss consisting of one-third of tubular structures; grade $\mathbf{2}$ - addition for grade 1, nuclear loss ranging from two-thirds of tubular structures; grade 3 - changes including nuclear loss which affects more than two-thirds of tubular structures.

\section{Statistical analysis}

SPSS for Windows 11.5 (SPSS Inc., Chicago, IL, USA) was used for the analysis of all data. The data were expressed in the form of mean (minimum, maximum) values for the histopathologic and biochemical parameters. While in the group comparison, the nonparametric Kruskal-Wallis test was employed, the Mann-Whitney $U$ test was employed in binary comparisons. The relationships between the parameters were evaluated according to Spearman's test. A p-value below 0.05 was considered to be statistically significant.

\section{RESULTS}

Biochemical results relevant to the study groups are shown in Table 1.

\section{Serum AST, ALT and MDA levels}

The Pringle maneuver induced hepatic $\mathrm{I} / \mathrm{R}$ injury. In the I/R group, serum ALT, AST, and MDA levels were found to be significantly higher when compared to the sham and control groups. In the groups with $\mathrm{I} / \mathrm{R}$ injury, the above-mentioned levels were significantly reduced by the administration of RA (Table 1).

\section{TOA, TAC and OSI levels}

Following I/R injury revealed that TOA, OSI, and TAC were increased, and TOA and OSI were significantly decreased by the administration of RA in the liver (Table 1).

Following $\mathrm{I} / \mathrm{R}$ injury indicated that TAC was increased, and TOA and OSI were significantly reduced by the administration of RA in the lung.

Following $\mathrm{I} / \mathrm{R}$ injury indicated no meaningful difference in TAC, TOA, and OSI among the groups in the kidney.

\section{Histopathologic evaluation}

Liver histopathologic scores were determined to be significantly higher in the I/R group when com- 
Table 1. Biochemical results relevant to the study groups

\begin{tabular}{lccccc}
\hline Parameters & \multicolumn{2}{c}{ Groups } & P* $^{*}$ \\
\cline { 2 - 5 } & Sham & Rosmarinic acid (RA) & Ischaemia/reperfusion (//R) & I/R + RA & \\
\hline MDA [ $\mu \mathrm{m} / \mathrm{L}]$ & $4.06 \pm 0.90$ & $3.70 \pm 1.18$ & $6.91 \pm 1.13^{\mathrm{a}, \mathrm{d}}$ & $4.50 \pm 0.94$ & 0.001 \\
ALT [IU/L] & $65.29 \pm 7.70$ & $59.15 \pm 13.12$ & $1076.63 \pm 463.81^{\mathrm{a}, \mathrm{d}}$ & $738.63 \pm 267.27^{\mathrm{a}, \mathrm{d}, \mathrm{f}}$ & $<0.001$ \\
AST [IU/L] & $62.75 \pm 18.53$ & $56.01 \pm 26.01$ & $930.63 \pm 229.70^{\mathrm{a}, \mathrm{d}}$ & $885.13 \pm 307.83^{\mathrm{a}, \mathrm{d}}$ & $<0.001$ \\
Liver-TAC [nmol Trolox equiv./mg] & $1.58 \pm 0.16$ & $1.86 \pm 0.57$ & $2.23 \pm 0.41^{\mathrm{b}}$ & $3.17 \pm 0.38^{\mathrm{a}, \mathrm{d}, \mathrm{f}}$ & $<0.001$ \\
Liver-TOA [nmol H202 equiv./mg] & $177.35 \pm 43.63$ & $100.87 \pm 14.95^{\mathrm{a}}$ & $252.16 \pm 53.53^{\mathrm{b}, \mathrm{d}}$ & $232.41 \pm 59.74^{\mathrm{c}, \mathrm{d}}$ & $<0.001$ \\
Liver-OSI & $11401.09 \pm 3095.31$ & $6044.304 \pm 2409.57^{\mathrm{b}}$ & $11667.57 \pm 3236.80^{\mathrm{d}}$ & $7419.18 \pm 2048.54^{\mathrm{g}}$ & $<0.001$ \\
Kidney-TAC [nmol Trolox equiv./mg] & $1.36 \pm 0.27$ & $1.96 \pm 0.54^{\mathrm{c}}$ & $1.53 \pm 0.18$ & $1.99 \pm 0.90$ & 0.074 \\
Kidney-TOA [nmol H $\mathrm{O}_{2}$ equiv./mg] & $61.71 \pm 14.49$ & $58.95 \pm 15.39$ & $67.12 \pm 14.43$ & $63.17 \pm 16.60$ & 0.738 \\
Kidney-OSI & $4726.70 \pm 1424.15$ & $3058.25 \pm 477.61^{\mathrm{b}}$ & $4456.05 \pm 1056.01^{\mathrm{e}}$ & $4647.90 \pm 3924.04$ & 0.076 \\
Lung-TAC [nmol Trolox equiv./mg] & $1.33 \pm 0.34$ & $1.95 \pm 0.72$ & $2.54 \pm 0.48^{\mathrm{a}}$ & $3.10 \pm 0.62^{\mathrm{a}, \mathrm{e}, \mathrm{h}}$ & $<0.001$ \\
Lung-TOA [nmol H $\mathrm{O}_{2}$ equiv/mg] & $72.66 \pm 8.36$ & $46.22 \pm 18.27^{\mathrm{b}}$ & $104.71 \pm 24.29^{\mathrm{a}, \mathrm{d}}$ & $94.50 \pm 13.65^{\mathrm{b}, \mathrm{d}}$ & $<0.001$ \\
Lung-OSI & $5941.06 \pm 2402.36$ & $2810.22 \pm 1805.89^{\mathrm{c}}$ & $4286.03 \pm 1397.50$ & $3147.05 \pm 770.17^{\mathrm{a}, \mathrm{h}}$ & 0.005 \\
\hline
\end{tabular}

Data are shown as mean \pm standard deviation; *Kruskal-Wallis test; a Significantly different from Sham group ( $p \leq 0.001$ ); ${ }^{\circ}$ Significantly different from Sham group ( $p \leq 0.01$ ); ${ }^{\circ}$ Significantly different from Sham group $(p<0.05)$; 'Significantly different from RA group $(p \leq 0.001)$; ${ }^{e}$ Significantly different from $R A$ group ( $p \leq 0.01$ ); fSignificantly different from I/R group ( $p \leq 0.001$ );

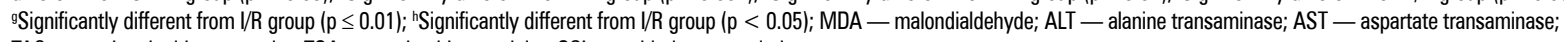
TAC — total antioxidant capacity; TOA — total oxidant activity; OSI — oxidative stress index

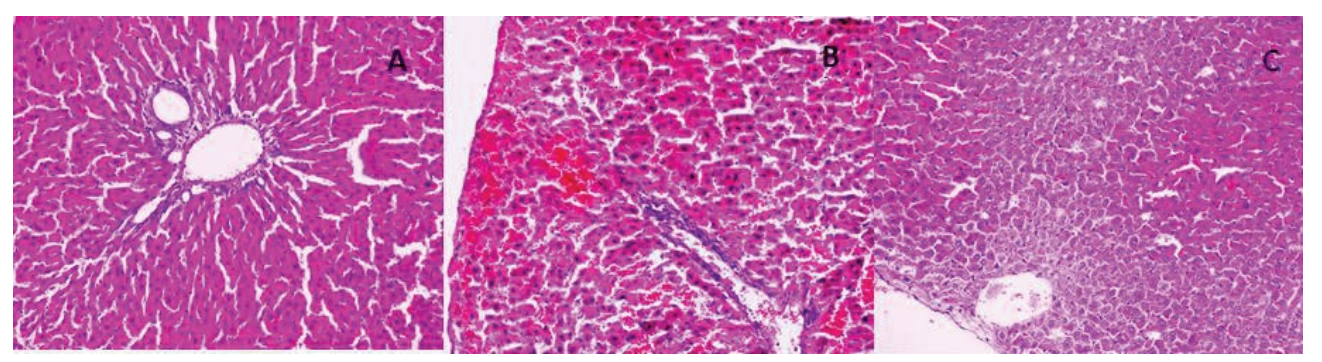

Figure 1. Effects of rosmarinic acid (RA) on the liver after ischaemia/reperfusion (I/R) evaluated by histological examination; A. A normal histopathological view in a rat from the sham group $(\mathrm{H} \& \mathrm{E}, 200 \times)$; B. An area representing nuclear pyknosis, cytoplasmic hypereosinophilia and loss of intercellular borders in a rat from the $\mathrm{I} / \mathrm{R}$ group $(\mathrm{H \& E}, 200 \times)$; C. An area representing cytoplasmic vacuolisation and nuclear pyknosis in a rat from the $\mathrm{l} / \mathrm{R}+\mathrm{RA}$ group $(\mathrm{H} \& \mathrm{E}, 200 \times)$.

pared to the other groups $(\mathrm{p}<0.001)$. Administration of RA markedly improved hepatic l/R injury (Figs. 1, 2).

Histopathologic evaluation of the kidney and lung sections following hepatic $\mathrm{l} / \mathrm{R}$ injury revealed no significant difference among the groups.

\section{DISCUSSION}

The Pringle maneuver is a surgical technique commonly performed during liver surgery to prevent intraoperative blood loss in the liver. They reported that the Pringle manoeuvre resulted in less blood loss per square centimetre of transection area $\left(12 \mathrm{~mL} / \mathrm{cm}^{2} \mathrm{vs} .22 \mathrm{~mL} / \mathrm{cm}^{2}\right.$, $\mathrm{p}=0.0001)$, a shorter transection time per square centimetre of transection area $\left(2 \mathrm{~min} / \mathrm{cm}^{2}\right.$ vs. $2.8 \mathrm{~min} / \mathrm{cm}^{2}$,

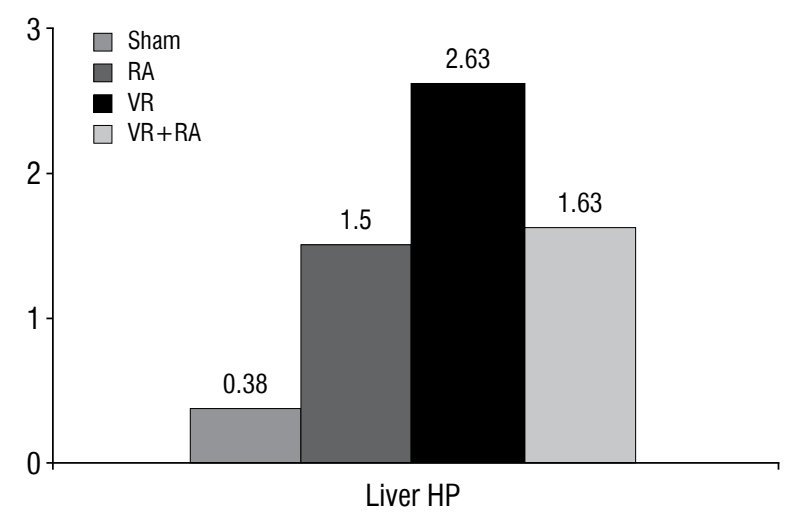

Figure 2. Liver histopathological (HP) scores levels of groups; $\mathrm{I} / \mathrm{R}$ - ischaemia/reperfusion; RA — rosmarinic acid. 
$p=0.016)$, a significantly higher arterial ketone body ratio in the first 2 hours after hepatectomy, lower serum bilirubin levels in the early postoperative period, and, in cirrhotic patients, higher serum transferrin levels on postoperative days 1 and 8 [19]. The most common complication caused by the Pringle maneuver is $1 / R$ injury. In the long term, the Pringle maneuver provides many advantages for surgeons but presents a high risk of $\mathrm{I} / \mathrm{R}$ injury. Ischaemia induced by vascular occlusion also leads to injury in the liver and distant organs, but reperfusion leads to severe injury. Furthermore, depletion of cellular energy, the activation of multiple enzyme systems and the accumulation of calcium and intracellular sodium and ROS are caused by ischaemia, which leads to cell damage $[32,36]$. Ulger et al. [36] aimed to investigate the protective effects of nebivolol in a hepatic $1 / R$ injury model. And, they suggested that nebivolol has protective effects histopathologically on liver but not on kidney and lung sections. Free oxygen radicals induced by reperfusion trigger cellular events such as inflammation, necrosis, hepatocellular damage and apoptosis. Free radicals lead to damage in all components of the cell, including DNA, proteins, and lipids. Supplementation of free radical scavengers has been shown to be useful in the reduction of tissue injury caused by $\mathrm{l} / \mathrm{R}[6,14,24,30,36]$.

Phenolic acids are powerful antioxidants and can scavenge nearly all oxidant molecules, for example, free radicals, can be scavenged by them through their hydroxyl groups. One or two powerful oxidant molecules can be scavenged by each of these compounds through their highly hydroxylated molecular properties $[33,35]$. Among the phenolic acids, RA shows maximum activity in the scavenging of free radicals and reduction of power and the chelating effect [33].

The strong antioxidant capacity of RA has been shown to alleviate injury in biological systems by removing ROS [6, 23]. In the study by Osakabe et al. [25], oral supplementation with RA was shown to treat seasonal allergic rhinoconjunctivitis by preventing inflammation and removing ROS. They concluded that the effect of RA on seasonal allergic rhinoconjunctivitis stemmed from two independent mechanisms: inhibition of the inflammatory response and clearance of reactive oxygen species. Han et al. [12] investigated whether RA has an anti-Warburg effect in gastric cancer in vitro and in vivo. In addition, anti-Warburg mechanisms of action have also been evaluated. As a result, they found that RA suppresses the Warburg effect in vivo. Ramalho et al. [29] also reported that RA exerts strong anti-inflammatory and antioxidant effects, and thus liver parenchymal cells are protected against I/R injury. The mechanisms underlying these effects have suggested that RA was associated with the inhibitory potential of the nuclear factor-kappaB signalling pathway and its natural antioxidant properties, as well as the reduction of endothelial and inducible nitric oxide synthase expression and nitric oxide levels. RA ( $50 \mathrm{mg} / \mathrm{kg}$ via oral gavage) was found to protect the liver by counteracting I/R injury-induced increases in serum transaminase levels and MDA, a free oxygen radical. Additionally, RA counteracted $\mathrm{I} / \mathrm{R}$ injury-induced increases in TOA and decreases in TAC in this study. In an experimental study, Rocha et al. [30] observed that administration of RA and extract at the dose of $25 \mathrm{mg} / \mathrm{kg}$ reduced paw oedema at 6 hours by over $60 \%$, exhibiting a dose-response effect, suggesting that rosmarinic was the main contributor to the antiinflammatory effect. And they also observed that RA was administered at $25 \mathrm{mg} / \mathrm{kg}$ (i.v.) $30 \mathrm{~min}$ prior to the induction of ischaemia and led to the significant reduction in the serum concentration of transaminases (AST and ALT) and lactate dehydrogenase in the liver $\mathrm{I} / \mathrm{R}$ model [30].

The free oxygen radicals induced by $I / R$ injury are considered to trigger cellular events, such as inflammation, hepatocellular damage, necrosis and apoptosis $[2,24]$. An experimental study found that $\mathrm{I} / \mathrm{R}$ resulted in vast areas of coagulation necrosis with infiltration of inflammatory cells and disintegration of hepatocyte cords; RA reduced these changes [29]. In our study, grade II and III changes (neutrophil infiltration, severe necrosis, and haemorrhage) were found in the liver sections of rats with hepatic $l / R$, which decreased to grade I and II changes (cytoplasmic vacuolisation and nuclear pyknosis) with the administration of RA.

Ischaemia/reperfusion injury induced by the Pringle maneuver mainly affects the lung and kidney, as well as other distant organs [24, 39]. Pulmonary microvascular endothelial cells are the primary target of mediators induced by $\mathrm{I} / \mathrm{R}$ injury. The release of pro-inflammatory mediators occurs after $\mathrm{I} / \mathrm{R}$ injury and they cause the impairment of the integrity of the endothelium and an increase in the permeability and deterioration of the lung endothelium [21, 36]. Numerous studies have shown that the lung injury may occur following hepatic $I / R[14$, $21,24,26]$. Histopathologically in the lung sections, mild-moderate neutrophil leukocyte infiltration with interstitial congestion was detected in $\mathrm{I} / \mathrm{R}$ and $\mathrm{I} / \mathrm{R}+\mathrm{RA}$ groups, and also the formation of perivascular oedema and fragmented pulmonary structures were found in $\mathrm{l} / \mathrm{R}$ group. But as stated in the literature, there were no significant difference between $\mathrm{V} / \mathrm{R}$ and $\mathrm{I} / \mathrm{R}+\mathrm{RA}$ group. 
Similarly, in the current study, although administration of RA decreased oxidative stress and ameliorated reductions in antioxidant capacity in the lung resulting from hepatic I/R injury, administration of RA caused no histopathologic changes. These findings suggest that further studies are needed to investigate the impacts of RA against $\mathrm{I} / \mathrm{R}$ injury in the lung.

The kidney is also affected by $I / R$ injury; acute renal failure is caused by major hepatic $1 / R$ in $40-85 \%$ of cases with high morbidity and mortality $[18,28]$. Hepatic $\mathrm{I} / \mathrm{R}$ has been shown to be responsible for damage to kidney [21], and numerous studies have reported on the prevention of renal injury after hepatic $\mathrm{I} / \mathrm{R}[14,24,36]$. Of these, the study by Ozturk et al. [27] reported that RA reduced I/R injury in the kidney by reducing oxidative stress. They concluded that there was a decrease in serum creatinine and blood urea nitrogen levels compared to other groups in the treatment of rats with RA. However, they also stated that there was no statistically significant difference. In the I/R group, malondialdehyde and myeloperoxidase levels decreased, while glutathione peroxidase and superoxide dismutase levels remained unchanged. According to histopathological results, they stated that RA causes focal glomerular necrosis, dilatation of Bowman capsule, degeneration of tubular epithelium, necrosis of tubular epithelium and a significant decrease in tubular dilatation [27]. In contrast to these studies, our study found no effects of RA on the prevention of renal injury after hepatic I/R injury. Histopathologically, $I / R$ and $I / R+R A$ groups had swelling of tubular cells, brush edge loss, nuclear condensation showing nuclear loss and nuclear loss extending from two out of three of tubular structures. In addition, in I/R group, nuclear losses included more than two out of three of tubular structures but this difference was not significant.

\section{CONCLUSIONS}

Despite the results, there are a few limitations in clinical contribution. RA decreases oxidative stress, increases antioxidant capacity, and leads to significant histopathologic improvement in the liver after hepatic I/R injury. These results indicate that RA acts as an antioxidant and is an effective hepatoprotective agent. However, although RA reduced lung oxidative stress and increased antioxidant capacity in the lung, no difference was observed in histopathology. Furthermore, no beneficial effect of RA on renal injury was found. Further studies are needed to analyse the effects of RA on distant organs.

\section{REFERENCES}

1. Aktan B, Taysi S, Gumustekin K, et al. Evaluation of oxidative stress in erythrocytes of guinea pigs with experimental otitis media and effusion. Ann Clin Lab Sci. 2003; 33(2): 232-236, indexed in Pubmed: 12817629.

2. Arab HA, Sasani F, Rafiee MH, et al. Histological and biochemical alterations in early-stage lobar ischemia-reperfusion in rat liver. World J Gastroenterol. 2009; 15(16): 1951-1957, doi: 10.3748/wjg.15.1951, indexed in Pubmed: 19399926.

3. Bolukbas C, Bolukbas FF, Horoz M, et al. Increased oxidative stress associated with the severity of the liver disease in various forms of hepatitis B virus infection. BMC Infect Dis. 2005; 5: 95, doi: 10.1186/1471-2334-5-95, indexed in Pubmed: 16262897.

4. Böyük A, Onder A, Kapan M, et al. Ellagic acid ameliorates lung injury after intestinal ischemia-reperfusion. Pharmacogn Mag. 2011; 7(27): 224-228, doi: 10.4103/09731296.84236, indexed in Pubmed: 21969793.

5. Chatterjee PK, Patel NSA, Kvale EO, et al. Inhibition of inducible nitric oxide synthase reduces renal ischemia/reperfusion injury. Kidney Int. 2002; 61(3): 862-871, doi: 10.1046/j.15231755.2002.00234.x, indexed in Pubmed: 11849439.

6. Choi HR, Choi JS, Han YN, et al. Peroxynitrite scavenging activity of herb extracts. Phytother Res. 2002; 16(4): $364-$ -367, doi: 10.1002/ptr.904, indexed in Pubmed: 12112294.

7. Chu X, Ci X, He J, et al. Effects of a natural prolyl oligopeptidase inhibitor, rosmarinic acid, on lipopolysaccharide-induced acute lung injury in mice. Molecules. 2012; 17(3): 3586-3598, doi: 10.3390/molecules17033586, indexed in Pubmed: 22441336.

8. Domitrović R, Skoda M, Vasiljev Marchesi V, et al. Rosmarinic acid ameliorates acute liver damage and fibrogenesis in carbon tetrachloride-intoxicated mice. Food Chem Toxicol. 2013; 51: 370-378, doi: 10.1016/j. fct.2012.10.021, indexed in Pubmed: 23116643.

9. Erel O. A new automated colorimetric method for measuring total oxidant status. Clin Biochem. 2005; 38(12): 1103-1111, doi: 10.1016/j.clinbiochem.2005.08.008, indexed in Pubmed: 16214125.

10. Erel O. A novel automated method to measure total antioxidant response against potent free radical reactions. Clin Biochem. 2004; 37(2): 112-119, doi: 10.1016/j. clinbiochem.2003.10.014, indexed in Pubmed: 14725941.

11. Hammouda el-R A, Khalil MM, Salem A. Lipid peroxidation products in pleural fluid for separation of transudates and exudates. Clin Chem. 1995; 41(9): 1314-1315, doi: 10.1093/clinchem/41.9.1314.

12. Han S, Yang S, Cai Z, et al. Anti-Warburg effect of rosmarinic acid via miR-155 in gastric cancer cells. Drug Des Devel Ther. 2015; 9: 2695-2703, doi: 10.2147/DDDT.S82342, indexed in Pubmed: 26056431.

13. Jordán MJ, Lax V, Rota MC, et al. Relevance of carnosic acid, carnosol, and rosmarinic acid concentrations in the in vitro antioxidant and antimicrobial activities of Rosmarinus officinalis (L.) methanolic extracts. J Agric Food Chem. 2012; 60(38): 9603-9608, doi: 10.1021/jf302881t, indexed in Pubmed: 22957812.

14. Kapan M, Gumus M, Onder A, et al. The effects of ellagic acid on the liver and remote organs' oxidative stress and structure after hepatic ischemia reperfusion injury caused by pringle 
maneuver in rats. Bratisl Lek Listy. 2012; 113(5): 274-281, doi: 10.4149/bll_2012_064, indexed in Pubmed: 22616584.

15. Kesik V, Guven A, Vurucu S, et al. Melatonin and $1400 \mathrm{~W}$ ameliorate both intestinal and remote organ injury following mesenteric ischemia/reperfusion. J Surg Res. 2009; 157(1): e97-e9e105, doi: 10.1016/j.jss.2008.12.024, indexed in Pubmed: 19394656.

16. Koksel O, Yildirim C, Cinel L, et al. Inhibition of poly(ADP-ribose) polymerase attenuates lung tissue damage after hind limb ischemia-reperfusion in rats. Pharmacol Res. 2005; 51(5): 453-462, doi: 10.1016/j.phrs.2004.11.007, indexed in Pubmed: 15749460.

17. Lee HJ, Cho HS, Park E, et al. Rosmarinic acid protects human dopaminergic neuronal cells against hydrogen peroxide-induced apoptosis. Toxicology. 2008; 250(2-3): 109-115, doi: 10.1016/j.tox.2008.06.010, indexed in Pubmed: 18644421.

18. Lee HT, Park SW, Kim M, et al. Acute kidney injury after hepatic ischemia and reperfusion injury in mice. Lab Invest. 2009; 89(2): 196-208, doi: 10.1038/labinvest.2008.124, indexed in Pubmed: 19079326.

19. Man K, Fan ST, Ng IO, et al. Prospective evaluation of Pringle maneuver in hepatectomy for liver tumors by a randomized study. Ann Surg. 1997; 226(6): 704-11; discussion 711, doi: 10.1097/00000658-199712000-00007, indexed in Pubmed: 9409569.

20. Mariani E, Cornacchiola V, Polidori MC, et al. Antioxidant enzyme activities in healthy old subjects: influence of age, gender and zinc status: results from the Zincage Project. Biogerontology. 2006; 7(5-6): 391-398, doi: 10.1007/ s10522-006-9054-6, indexed in Pubmed: 16967205.

21. Miranda LE, Capellini VK, Reis GS, et al. Effects of partial liver ischemia followed by global liver reperfusion on the remote tissue expression of nitric oxide synthase: lungs and kidneys. Transplant Proc. 2010; 42(5): 1557-1562, doi: 10.1016/j.transproceed.2010.02.097, indexed in Pubmed: 20620474.

22. Moon DO, Kim MO, Lee JD, et al. Rosmarinic acid sensitizes cell death through suppression of TNF-alpha-induced NF-kappaB activation and ROS generation in human leukemia U937 cells. Cancer Lett. 2010; 288(2): 183-191, doi: 10.1016/j.canlet.2009.06.033, indexed in Pubmed: 19619938.

23. Nunes S, Madureira AR, Campos D, et al. Therapeutic and nutraceutical potential of rosmarinic acid-cytoprotective properties and pharmacokinetic profile. Crit Rev Food Sci Nutr. 2017; 57(9): 1799-1806, doi: 10.1080/10408398.2015.1006768, indexed in Pubmed: 26114303.

24. Oguz A, Kapan M, Onder A, et al. The effects of curcumin on the liver and remote organs after hepatic ischemia reperfusion injury formed with Pringle manoeuvre in rats. Eur Rev Med Pharmacol Sci. 2013; 17(4): 457-466, indexed in Pubmed: 23467943.

25. Osakabe N, Takano H, Sanbongi C, et al. Anti-inflammatory and anti-allergic effect of rosmarinic acid (RA); inhibition of seasonal allergic rhinoconjunctivitis (SAR) and its mechanism. Biofactors. 2004; 21(1-4): 127-131, doi: 10.1002/ biof.552210125, indexed in Pubmed: 15630183.

26. Ota S, Nakamura K, Yazawa T, et al. High tidal volume ventilation induces lung injury after hepatic ischemia-rep- erfusion. Am J Physiol Lung Cell Mol Physiol. 2007; 292(3): L625-L631, doi: 10.1152/ajplung.00151.2006, indexed in Pubmed: 17056704.

27. Ozturk H, Ozturk H, Terzi EH, et al. Protective effects of rosmarinic acid against renal ischaemia/reperfusion injury in rats. J Pak Med Assoc. 2014; 64(3): 260-265, indexed in Pubmed: 24864596.

28. Park SW, Chen SWC, Kim M, et al. Human activated protein C attenuates both hepatic and renal injury caused by hepatic ischemia and reperfusion injury in mice. Kidney Int. 2009; 76(7): 739-750, doi: 10.1038/ki.2009.255, indexed in Pubmed: 19625989.

29. Ramalho LN, Pasta ÂA, Terra VA, et al. Rosmarinic acid attenuates hepatic ischemia and reperfusion injury in rats. Food Chem Toxicol. 2014; 74: 270-278, doi: 10.1016/j. fct.2014.10.004, indexed in Pubmed: 25455894.

30. Rocha J, Eduardo-Figueira M, Barateiro A, et al. Anti-inflammatory effect of rosmarinic acid and an extract of Rosmarinus officinalis in rat models of local and systemic inflammation. Basic Clin Pharmacol Toxicol. 2015; 116(5): 398-413, doi: 10.1111/bcpt.12335, indexed in Pubmed: 25287116.

31. Sahu A, Rawal N, Pangburn MK. Inhibition of complement by covalent attachment of rosmarinic acid to activated C3b. Biochem Pharmacol. 1999; 57(12): 1439-1446, doi: 10.1016/ s0006-2952(99)00044-1, indexed in Pubmed: 10353266.

32. Serracino-Inglott F, Habib NA, Mathie RT. Hepatic ischemia-reperfusion injury. Am J Surg. 2001; 181(2): 160-166, doi: 10.1016/s0002-9610(00)00573-0, indexed in Pubmed: 11425059.

33. Sevgi K, Tepe B, Sarikurkcu C. Antioxidant and DNA damage protection potentials of selected phenolic acids. Food Chem Toxicol. 2015; 77: 12-21, doi: 10.1016/j. fct.2014.12.006, indexed in Pubmed: 25542528.

34. Sotnikova R, Okruhlicova L, Vlkovicova J, et al. Rosmarinic acid administration attenuates diabetes-induced vascular dysfunction of the rat aorta. J Pharm Pharmacol. 2013; 65(5): 713-723, doi: 10.1111/jphp.12037, indexed in Pubmed: 23600389.

35. Sroka Z, Cisowski W. Hydrogen peroxide scavenging, antioxidant and anti-radical activity of some phenolic acids. Food Chem Toxicol. 2003; 41(6): 753-758, doi: 10.1016/ s0278-6915(02)00329-0, indexed in Pubmed: 12738180.

36. Ulger BV, Erbis H, Turkcu G, et al. Nebivolol ameliorates hepatic ischemia/reperfusion injury on liver but not on distant organs. J Invest Surg. 2015; 28(5): 245-252, doi: 10.3109/08941939.2015.1031923, indexed in Pubmed: 26305470.

37. Xu Y, Jiang Z, Ji G, et al. Inhibition of bone metastasis from breast carcinoma by rosmarinic acid. Planta Med. 2010; 76(10): 956-962, doi: 10.1055/s-0029-1240893, indexed in Pubmed: 20157877.

38. Xu Y, Xu G, Liu Li, et al. Anti-invasion effect of rosmarinic acid via the extracellular signal-regulated kinase and oxidation-reduction pathway in Ls174-T cells. J Cell Biochem. 2010; 111(2): 370-379, doi: 10.1002/jcb.22708, indexed in Pubmed: 20506543.

39. Zimmerman BJ, Granger DN, Zimmerman BJ, et al. Reperfusion injury. Surg Clin North Am. 1992; 72(1): 65-83, doi: 10.1016/s0039-6109(16)45628-8, indexed in Pubmed: 1731390. 